\title{
И.В. Новицкая
}

Томский государственный университет

\section{Моделирование поля словообразовательной категории абстрактных / отвлеченных имен в готском языке}

Аннотащия: В статье рассматривается категориальный статус совокупности словообразовательных формантов абстрактных имен в древнегерманских языках. На основе прототипического подхода к категории структурируется суффиксальный сегмент поля словообразовательной категории абстрактности в готском языке.

The article presents an attempt to consider a group of derivational suffixes of the old-germanic abstract nouns as a derivational category. Hence, a suffix segment of the derivational field of abstract nouns is modeled on the basis of the prototype approach to the category.

Ключевые слова: словообразовательная категория, словообразовательный тип, полевое моделирование, абстрактные имена существительные.

Word-building category, word-building type, modeling of a field, abstract nouns.

УДК: 811.11-112.

Контактная информащия: Томск, ул. Ленина, 36. ТГУ, факультет иностранных языков. Тел. (3822) 529695. E-mail: novitsky@mail.tomsknet.ru.

Настоящая статья посвящена обсуждению проблемы словообразовательной маркированности лексических единиц отдельного лексико-семантического разряда словарного состава древнегерманских языков - ЛСР абстрактных / отвлеченных имен существительных - с системной точки зрения. Дело в том, что признание того факта, что в древнегерманских языках существовали некоторые словообразовательные морфемы АИ / ОИ, не ведет к их дальнейшему анализу как определенным образом структурированной совокупности и, соответственно, к выявлению ключевого принципа организации сетки их взаимоотношений. Поэтому вопросы, которые последовательно будут затронуты в данной статье, нацелены на устранение означенного пробела и включают в себя следующие задачи: 1) рассмотрение возможности интерпретировать объединение древнегерманских формантов абстрактности / отвлеченности как словообразовательной категории (далее - СК), 2) описание принципов структурирования СК, 3) характеристику основных единиц СК и 4) моделирование отдельного сегмента поля СК АИ / ОИ.

Прежде всего, вывод о наличии словообразовательной категории абстрактности / отвлеченности в таких древнегерманских языках как готский, древнеисландский, древневерхненемецкий и древнеанглийский, базируется на эмпирических данных, полученных в результате сплошной выборки древнегерманских АИ / ОИ и анализе их словообразовательной структуры. Согласно полученным данным, девяносто процентов выделенных АИ / ОИ являются производными именами (в подавляющем большинстве - отглагольными и отыменными) и оформлены суффиксальными морфемами различной структурной сложности, относящимися к различным хронологическим пластам. Все выявленные словообразовательные элементы, продуцирующие значение абстрактности / отвлеченности, образуют 
относительно устойчивую совокупность, которая включает в себя стабильные единицы и в то же время обнаруживает тенденцию к расширению за счет новых единиц. Все словообразовательные элементы исследуемой совокупности выполняют сходную функцию - маркирование лексических единиц одной и той же семантической общности, единого денотативного пространства - ЛСР абстрактных / отвлеченных субстантивов. В общем, вся совокупность выявленных суффиксов АИ / ОИ представлена в следующей таблице.

Таблица 1.

Словообразовательные суффиксы АИ / ОИ в трех древнегерманских языках.

\begin{tabular}{|c|c|c|c|c|}
\hline Род & $\begin{array}{c}\text { Словообразо- } \\
\text { вательный эле- } \\
\text { мент }\end{array}$ & Готский & Ди. & Двн. \\
\hline \multirow[t]{2}{*}{$\begin{array}{l}\text { Ж. } \\
\text { p. }\end{array}$} & Основ. суф. & $\begin{array}{c}\text {-ō-, -ein-, -jō-, -ōn- } \\
\text {-jōn, -wōn- }\end{array}$ & -ōn-, -jōn-, -īn- & $\begin{array}{c}\text {-ō-, }-\overline{1}(\mathrm{n})- \\
\text {-ōn- }\end{array}$ \\
\hline & Суф. & $\begin{array}{c}\text {-ipa-/-ida-, } \\
\text { *-ti-, } \\
\text { *-ni-, } \\
\text {-eini-, -aini-, -ōni-, } \\
\text {-dupi-, } \\
\text {-ubni-/-ufni-, } \\
\text { *-pwō- }\end{array}$ & $\begin{array}{c}\text {-semd-/-semi-, } \\
\text {-an-/-un-, } \\
\text {-n- (<-inni-, -ēni-), } \\
\text {-ing-/-ung-, } \\
\text {-ska-/-zla-, -skja-, } \\
\text {-(n)eskja- } \\
\text {-sla-/-zla-, } \\
\text {-endi-/-indi-, } \\
\text {-átta-, } \\
\text {-ð-, -d-, -t- }(<* \text { *- } \\
\text { ipō-, *-ði-), } \\
\text {-osta-/-usta-, -ni-/- } \\
\text { sni- }\end{array}$ & $\begin{array}{c}\text {-scaf(t)-, } \\
\text {-heit-, } \\
\text {-nissa-, -nessī-, } \\
\text {-unga-, } \\
\text {-unna-, } \\
\text {-ida-/-eda-, } \\
\text {-nussida-/-nissida- } \\
, \\
\text {-t-, -st-, } \\
\text {-ft- }\end{array}$ \\
\hline \multirow[t]{2}{*}{$\begin{array}{l}\text { M. } \\
\text { p. }\end{array}$} & Основ. суф. & -u-, -in-/-an & -an- & -an- \\
\hline & Суф. & $\begin{array}{c}\text { *-tu-, } \\
\text {-opu-/-odu-, } \\
\text {-assu-, -inassu- }\end{array}$ & $\begin{array}{c}\text {-skapr-, -dómr-, } \\
\text {-leikr-/-leiki-, } \\
\text {-ingr-/-ungr-, } \\
\text {-aðr-/-uðr- (<-ōðu- } \\
\text { ), } \\
\text {-naðr-, -dr-/-tr-/-ðr-, } \\
\text {-t-/-st- }\end{array}$ & $\begin{array}{l}\text {-tuom-, } \\
\text {-ōd-/-ōt- }\end{array}$ \\
\hline \multirow[t]{2}{*}{$\begin{array}{l}\text { Cp. } \\
\text { p. }\end{array}$} & Основ. суф. & -ja- & -ja- & -ja- \\
\hline & Суф. & $\begin{array}{c}\text { *-isko- } \\
\text {-ubni-/-ufni- } \\
\text { *-pwa- }\end{array}$ & $\begin{array}{c}\text {-lœti-, } \\
\text {-erni-, } \\
\text {-sl-, } \\
\text {-endi--indi- }\end{array}$ & $\begin{array}{c}\text {-tuom-, -nissi-, } \\
\text {-sal-, -isal- } \\
\text {-ōd-/-ōt-, } \\
\text {-d-, -t-, } \\
\text {-izzi-, -tar- }\end{array}$ \\
\hline
\end{tabular}

Следовательно, выявленную группу словообразовательных элементов можно охарактеризовать как устойчивую совокупность морфем, которая выполняет единую функцию маркера абстрактного / отвлеченного содержания. Данная совокупность реализует в языке словообразовательную категорию абстрактности / отвлеченности, под которой в целом понимается «единство словообразовательного значения при различии средств выражения» [Земская, 1992, с. 25], или «класс лек- 
сем, которые характеризуются единой деривационной функцией» [Stekauer, Lieber, 2005, c. 227].

На этом этапе необходимо сделать важное замечание о качественном составе рассматриваемой категории. Как следует из таблицы, приведенный список включает исключительно суффиксальные морфемы 2 типов: собственно суффиксы и основообразующие суффиксы. Данное обстоятельство вовсе не означает, что префиксальные морфемы полностью отсутствуют в морфологической структуре анализируемых древнегерманских АИ / ОИ. Напротив, исследованный материал показал, что префиксальные морфемы достаточно широко представлены в древнегерманских словах. Тем не менее, исключение префиксальных морфем из дальнейшего анализа вызвано объективными причинами, а именно, прежде всего, общепринятой точкой зрения о том, что на германском уровне о наличии подлинных префиксальных морфем можно говорить только в тех случаях, когда они одновременно не функционировали в языке в качестве наречий или предлогов [СГГЯ, 1963, с. 56; Гухман, 1958, с. 205]. Также известно, что префиксация в именном словообразовании германских языков играла меньшую роль по сравнению с глагольной [СГГЯ, 1963, с. 64], поэтому префиксальными в подлинном смысле слова считаются имена, образованные от существительных. При производстве отглагольных существительных «наличие префикса в составе существительного свидетельствует лишь о том, что последнее было создано от производной (префиксальной) основы - в подавляющем большинстве случаев от глагольной, а несколько реже - от адъективной» [СГГЯ, 1963, с. 65]. В-третьих, согласно замечаниям исследователей [Смирницкий, 1955, с. 165; Ильиш, 1958, с. 63; Дронова, 2008, с. 51], префиксальные морфемы в структуре древнегерманских слов могли, с одной стороны, выступать в качестве словообразовательных формантов, а с другой - составных элементов сложных слов. Однако, благодаря процессам семантического опро́щения префиксов («пустые» префиксы), многозначности префиксов, засвидетельствованной в древнегерманских словах, генетической связи префиксов с предлогами и наречиями, часто функционирующими в языке параллельно с префиксальными элементами, невозможно с абсолютной уверенностью констатировать функциональный статус префиксальных морфем в структуре существительных.

Приведенные факты позволяют считать, что роль префиксации в образовании АИ / ОИ в трех исследуемых языках невозможно считать до конца выясненной, поэтому анализ АИ / ОИ в настоящей работе ограничен сферой суффиксальной деривации.

Дальнейшее исследование этимологии выделенных суффиксов позволило установить хронологическую многослойность всей категории. Так, все древнегерманские суффиксальные элементы по времени вхождения в словообразовательную категорию АИ / ОИ, можно распределить на несколько слоев, в каждом из которых возможно дальнейшее дробление, например:

1. суффиксы раннеобщеи.-е. языкового состояния, куда относятся древнейшие основообразующие суффиксы -u-, -о̄-, -a-, -i-, -ja-, -jō-.

2. суффиксы общеи.-е происхождения: *-ti-, *-tu-, *-to-/-tā- и *-ni-, а также *-tlo-, *-tro-, *-men-, *-two-/-twā и *-k-, которые в самостоятельном употреблении в древнегерманских языках были уже непродуктивны, однако послужили источниками для формирования общегерманских суффиксов.

3. общегерманские суффиксы, для которых также различается время вхождения в систему. 


\begin{tabular}{|c|c|c|c|}
\hline Готский & Ди. & Двн. & Да. \\
\hline -dupi- (F) & - & - & - \\
\hline $\begin{array}{l}\text {-assu- (M) } \\
\text {-inassu- (M) }\end{array}$ & - & $\begin{array}{l}\text {-nissa- (F) } \\
\text {-nessī- (F) } \\
\text {-nissi- (N) }\end{array}$ & $\begin{array}{l}\text {-nes-/-nys-/-nis- } \\
\text { (F) }\end{array}$ \\
\hline $\begin{array}{l}\text {-eini- }(F) \\
\text {-aini- }(F) \\
\text {-ōni- (F) }\end{array}$ & $\begin{array}{c}\text {-an-/-un- (F) } \\
\text {-n- (F) }\end{array}$ & $-\overline{1} n-/-\overline{1}-(F)$ & -en- $(F, N)$ \\
\hline- & $\begin{array}{c}\text {-ing-/-ung- }(\mathrm{F}, \mathrm{M}) \\
\text {-ning- }(\mathrm{M})\end{array}$ & -unga- (F) & $\begin{array}{c}\text {-ing-/-ung- }(\mathrm{F} \\
\mathrm{M}) \\
\text {-ling- }(\mathrm{M})\end{array}$ \\
\hline -sl- (N) & -sla-/-zla- (F) -sl- (N) & $\begin{array}{l}\text {-sal-, -isal-, -islia- } \\
(\mathrm{N}, \mathrm{F})\end{array}$ & $\begin{array}{l}\text {-els-/-else-, -elsa- } \\
\text { (M) }\end{array}$ \\
\hline -isk- (прил.) & $\begin{array}{c}\text {-ska-/-zka- (F) } \\
\text {-skja- (F) } \\
\text {-(n)eskja- (F) } \\
\end{array}$ & -isc- (прил.) & -isc- (прил.) \\
\hline -ubni-/-ufni- $(\mathrm{F}, \mathrm{N})$ & - & $\begin{array}{c}\text {-unna- }(<* \text {-innjō- }) \\
(\mathrm{F}) \\
\text {-inna- } \\
\end{array}$ & $\begin{array}{c}\text {-en- }(<* \text {-innjō- }) \\
(\mathrm{F}) \\
(<* \text {-unnia- })(\mathrm{N})\end{array}$ \\
\hline -ōpu-/-ōdu- (M) & $\begin{array}{c}\text {-aðr-/-uðr- (M) } \\
\text {-naðr- (M) }\end{array}$ & $\begin{array}{c}\text {-ōd-/-ōt- (M) } \\
\text {-isōd- (M) }\end{array}$ & $\begin{array}{l}\text {-оð-/-að- (M) } \\
\text {-noð-/-nað- (M) }\end{array}$ \\
\hline -ipa-/-ida- (F) & $-ð-,-d-,-t-(F)$ & $\begin{array}{c}\text {-ida-/-eda- (F) } \\
\text {-id̄i- (F) }\end{array}$ & $\begin{array}{c}\text {-ð-, -p-, -ðu-/-ðo- } \\
\text { (F) }\end{array}$ \\
\hline $\begin{array}{c}-\mathrm{t}-,-\mathrm{d}-,,-\mathrm{p}-,,-\mathrm{ss}-(\mathrm{F}) \\
(>*-\mathrm{ti}-)\end{array}$ & -ð-, -d-, -t- (F) & -t-, -d- (F) & -t-, -ð- \\
\hline- & - & -nussida-/-nissida- (F) & - \\
\hline- & -átta- (F) & - & - \\
\hline -pwa-/-pwō- $(\mathrm{N}, \mathrm{F})$ & - & - & - \\
\hline -pr-, -dr-, -tr- $(\mathrm{F}, \mathrm{N})$ & $\begin{array}{c}\text {-ðr-, -dr-, -tr-, -ttr- } \\
(\mathrm{M})\end{array}$ & $-\operatorname{tar}-(\mathrm{N})$ & $\begin{array}{l}\text {-ðor-, -dor-, -tor- } \\
(\mathrm{M}, \mathrm{N})\end{array}$ \\
\hline$-\mathrm{p}-(\mathrm{N}, \mathrm{F}, \mathrm{M})$ & $\begin{array}{c}\text {-d-, -t-, -ठ- } \\
(\mathrm{N}, \mathrm{M})\end{array}$ & -d-, -t- (M, N) & -d-, -t-, -ठ- (M) \\
\hline -pla-, -tuli- $(\mathrm{N}, \mathrm{F})$, & - & -tal-, -dal- & $-\mathrm{tl}-$ \\
\hline- & $\begin{array}{l}\text {-endi-/-indi-/-yndi- } \\
\text { (F) }\end{array}$ & - & - \\
\hline- & -erni- $(\mathrm{N})$ & - & - \\
\hline- & -osta-/-usta- (F) & - & - \\
\hline
\end{tabular}

К этой же группе можно отнести и самые «молодые» основообразующие суффиксы: -о̄n-, -jōn, -wōn-, -ī(n)-.

4. древнегерманские суффиксы, образованные из самостоятельных слов.

\begin{tabular}{|c|c|c|c|}
\hline Готский & Ди. & Двн. & Да. \\
\hline отсутствуют & -skapr- (M) & -scaf(t)- (F) & -scipe- (M) \\
& -dómr- (M) & -tuom- (M, N) & -dōm- (M) \\
& - -lœti- (N) & - & - \\
& - & - heit- (F) & -hād- (M) \\
& -semd-/-semi- (F) & - & - \\
& - & - & -rāēden- (F) \\
& -leikr-/-leiki (M) & - & -lāc- (N) \\
\hline
\end{tabular}

Установив категориальный характер совокупности словообразовательных суффиксов АИ / ОИ, перейдем к рассмотрению принципов структурирования данной категории. 
В рамках когнитивной платформы, которая рассматривает словообразование как деятельность, ориентированную на оптимизацию и обеспечение познавательной деятельности человека, на вербализацию духовной жизни человека и воспринятого им мира, многочленные ряды номинативных единиц, созданные по определенным словообразовательным моделям и имеющие сходный компонент содержания, формируют категории, имеющие полевой принцип организации [Кубрякова, 2004; Араева, 2009].

Полевый, или прототипический, подход к описанию языковой системы в целом и отдельных ее элементов в частности не является новым и разрабатывается с конца XIX в., но в настоящий момент с учетом исследований в рамках когнитивной парадигмы он применяется для обозначения не только явлений лексикосемантического уровня, но и для единиц фонетического, словообразовательного, морфологического, синтаксического уровней [Гулыга, Шендельс, 1969; Щур, 1974; Караулов, 1976; Кобозева, 2000 и др.].

Полевый принцип организации словообразовательной категории предполагает, с одной стороны, наличие структурных единиц, которые, располагаясь на разном удалении от центра, вступают друг с другом в парадигматические отношения и формируют участки поля различной семантической насыщенности, а с другой - наличие понятийной сущности, которая выступает как интегрирующее основание для элементов поля.

Центральное место в категории отводится прототипу, для которого выделяются следующие существенно важные признаки: 1) наибольшая специфичность, т.е. концентрация в прототипе специфических признаков данного объекта, «центральность», в отличие от разреженности таких признаков на периферии (в окружении прототипа); 2) способность к воздействию на производные варианты, статус «источника производности»; 3) наиболее высокая степень регулярности функционирования (признак возможный, но необязательный). Следовательно, в отношении языковых единиц, классов и категорий прототип - это наиболее репрезентативный вариант определенного инвариантного системного объекта, характеризующийся наибольшей специфичностью (концентрацией специфических признаков данного объекта), способностью к воздействию на производные варианты (признак «источник производности») и (во многих случаях) наиболее высокой степенью регулярности функционирования. Иными словами, прототип - это эталонный репрезентант (эталонный вариант) определенного инварианта среди прочих его представителей (вариантов) [КСКТ, 1996, с. 140; Демьянков, 1994, с. 37; Скребцова, 2007, с. 50].

Как указывает В.3. Демьянков [Демьянков, 1994, с. 40], критерии отнесения к прототипу носят скорее универсальный, чем случайный характер. В рамках словообразовательных категорий предлагается выделять ядро и периферию на основе понятия продуктивности: а) качественной, т.е. системной (способность к активному словообразованию, значимость словообразовательного типа в словообразовательной системе языка) и б) количественной, т.е. эмпирической (распространенность данного типа производных в языковом материале, протяженность словообразовательного ряда) [Логутенкова, 1993, с. 77; Араева, 2009, с. 57]. При определении степени продуктивности словообразовательного типа в диахронии следует учитывать еще три критерия: грамматический, типологический, а также хронологический [Casaretto, 2000, S. 213-214].

Таким образом, прототипический подход определяет категорию как объединение членов с неравным статусом, т.е. с неполностью повторяющимися признаками. Один из членов категории может обладать привилегированным положением, являя собой лучший образец своего класса (прототип) и, тем самым, наиболее полно отвечая представлению о сути объединения и его прототипе, вокруг которого группируются остальные члены [КСКТ, 1996, с. 46; Кубрякова, 2004, с. 310; Скребцова, 2007, с. 50]. Каждая категория включает члены, описывающие опре- 
деленное денотативное пространство и распределяющиеся по всему пространству категориального поля в зависимости от степени приближенности к прототипу.

В современных исследованиях системы словообразования языка [Резанова, 1996; Араева, 2009] в качестве базовой простой единицы словообразования признается производное слово, а в качестве мельчайшей комплексной единицы словообразовательной категории - словообразовательный тип.

В свою очередь, комплексная единица СК словообразовательный тип (СТ) понимается как «семантическая микросистема, по своей сути являющаяся ментально-языковой категорией, члены которой соотносятся между собой по принципу радиальной метонимии, то есть по принципу фамильного сходства», иными словами это формально-семантическая микросистема, устроенная по принципу поля, и имеющая размытые формально-семантические границы [Араева, 2009, c. 12,75$]$. Словообразовательный тип тем самым определяется как «совокупность структурно единообразных производных нескольких (или одного) номинативных классов, объединенных одним обобщенным словообразовательным значением» [Там же, с. 19]. Данная микросистема построена по типу естественных категорий, то есть поля, и, следовательно, имеет центр и периферию, заполненные производными от одной части речи со сходным словообразовательным значением. Поскольку словообразовательное значение понимается как иерархически организованная семантическая единица [Там же, с. 27], то в его структуре выделяются значения разного уровня абстракции [Там же, с. 30-44]. Словообразовательный тип, таким образом, рассматривается как полевая структура, которая включает в себя комплекс микрополей - видов словообразовательных значений, соотносящихся друг с другом по иерархическому принципу.

Основными критериями выделения СТ являются: 1) критерий тождества частеречной принадлежности мотивирующих единиц (= мономотивация), 2) критерий тождества форманта и 3) критерий специфики семантического рисунка типа, причем каждый из этих критериев не является абсолютным [Там же, с. 66-76]. Отсюда, СТ есть метаязыковая, понятийная единица, которая обозначает схему построения производного слова, абстрагированную от лексических единиц с учетом единого частеречного оформления мотивирующих и мотивированных, тождества форманта и словообразовательного значения [Там же, с. 19].

Каждый СТ объединяет производные слова, имеющие сходную модель построения, иконическим образом отражающую общую пропозициональную структуру, лежащую в основе их содержания. Одна и та же пропозициональная структура производного слова может быть объективирована разными языковыми формами, что зависит от восприятия и концептуализации ситуации, наблюдаемой говорящим. Следовательно, ПС могут иметь сходное содержание, но разную степень семантической компрессии, когнитивной сложности и фокусировки на разных деталях описываемого, что маркируется определенными языковыми формами и тем самым сигнализирует об их семантической близости, но не тождественности. Это означает, что каждый СТ создает свой образ обозначенного, свой профиль значения [Кубрякова, 2004, с. 436], который зависит от способа представления информации в наименовании, а именно от того, на каких аспектах или деталях обозначаемого она сфокусирована.

Следовательно, на данном этапе рассуждений можно сделать заключение о том, что наличие совокупности словообразовательных формантов, маркирующих АИ / ОИ в древнегерманских языках, позволяет выделить словообразовательную категорию абстрактности. Каждый аффикс этой категории представляет отдельный словообразовательный тип, который, однако, характеризуется полимотивацией, то есть включает производные не только от одной части речи. Базовой минимальной единицей словообразовательных типов и категории в целом выступает производное имя, морфолого-деривационная структура которого иконически отражает некоторую пропозицию. Все словообразовательные типы словообразова- 
тельной категории абстрактности участвуют в структурировании поля данной категории.

Определение словообразовательной категории как комплексной единицы системы словообразования, полевая структура которой формируется совокупностью словообразовательных типов на базе общности словообразовательного значения, позволяет выработать методику конструирования словообразовательного поля понятийной категории абстрактности / отвлеченности.

В задачу описания экстенсионала словообразовательного поля абстрактности / отвлеченности входит характеристика лексических единиц, обозначающих абстрактные / отвлеченные понятия, с точки зрения их морфемного состава, наличия словообразовательных формантов и связей с производящими основами. Дальнейшее описание плана выражения поля предполагает структурирование его элементов (словообразовательных типов) от ядра к периферии на основе количественного показателя (эмпирической продуктивности).

Далее, на примере словообразовательных типов АИ / ОИ в готском языке смоделируем суффиксальный сегмент словообразовательного поля абстрактности / отвлеченности.

Показатели эмпирической продуктивности СТ абстрактности / отвлеченности позволяют распределить все СТ по трем зонам:

Схема 1. Словообразовательное поле абстрактности в готском языке

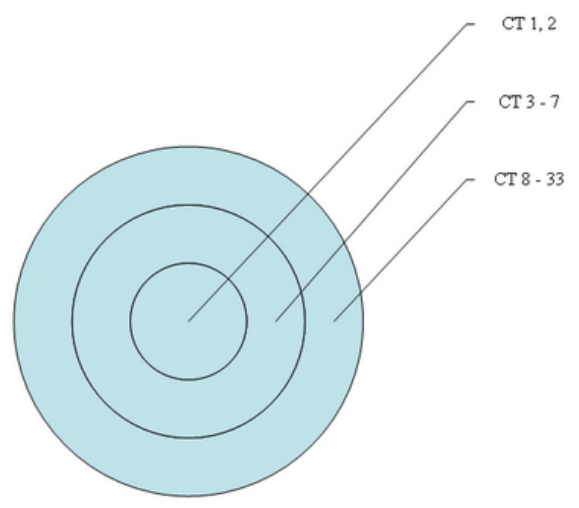

В данном поле выделяется зона ядра, срединный и периферийный участки. К околоядерной зоне относятся словообразовательные суффиксы с наиболее высокими количественными показателями. По мере уменьшения количественного показателя все суффиксы располагаются по всему полю на разном удалении от ядра.

Околоядерная зона: 1 - F ein (112 примеров)

$2-\mathrm{F}$ eini (88), aini (16), ōni (8) $=(112)$

Срединная зона: $\quad 3$ - F ti (65 примеров)

$4-\mathrm{N}$ a $(41)$

$5-\mathrm{N} \mathrm{ja}(41)$

$6-\mathrm{F}$ ipa (39)

$7-\mathrm{F} \overline{\mathrm{o}}(23)$ 


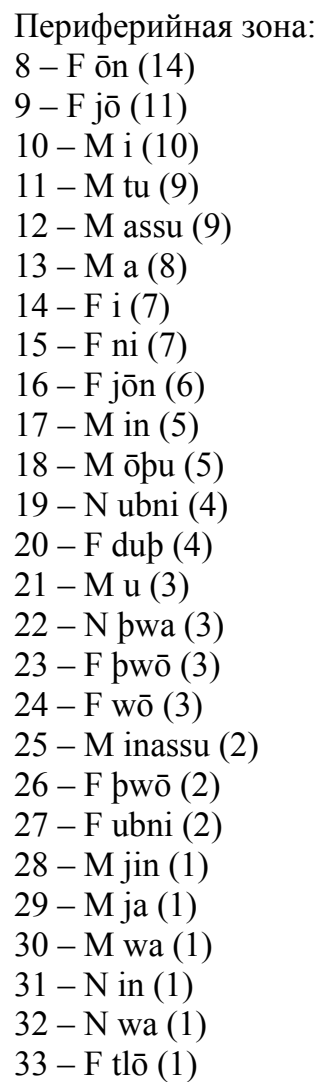

Приведенные данные позволяют увидеть, что в ядерной части поля располагаются словообразовательные типы 1 и 2, по модели которых образуются АИ / ОИ ж.р. от прилагательных (тип 1) и слабых глаголов (тип 2) при помощи назальных суффиксов -еin- и -ni-, относящихся к одному временному пласту самых молодых в готском языке суффиксов абстрактности. К срединному слою поля относятся СТ 3-7, включающие модель отглагольных производных ж.p. с суф. -ti- (тип 3), a также отыменных производных ж.р. с суф. -іра- (тип 6) и отглагольных производных ж.р. с суф. -о̄- (тип 7). Достаточно продуктивными в готском стали модели производных ср.р. от глаголов с основообразующими суффиксами -а- (тип 4) и -ја- (тип 5). Хронологически суф. -ti- и -іра- являются древнейшими суффиксами абстрактности, унаследованными из общеи.-е. языкового периода, причем суф. -tiдаже приравнивается к основообразующим суффиксам. Остальные суффиксы (-о̄-, -а- и -ја-) относятся к основообразующим формантам гласных типов склонения. Периферию словообразовательного поля формируют все остальные СТ (типы 8-33).

Введение дополнительных критериев (грамматического и хронологического) при моделировании поля словообразовательной категории абстрактности позволяет произвести некоторые уточнения в срединной и периферийной зонах поля. При учете особенностей парадигм производных с различными суффиксами и степени древности словообразовательных суффиксов выявляются следующие количественные показатели продуктивности словообразовательных моделей:

Околоядерная зона: $1-\mathrm{F}$ ein $=\mathbf{1 1 2}$ примеров

$2-\mathrm{F}$ eini (88), aini (16), ōni (8) = 112

Срединная зона: $\quad 3-$ F ti (65) + F i (7) + F ni (7) + F dup (4) $=\mathbf{8 3}$ 
$4-\mathrm{F}$ o (23) + F ipa (39) + F jō (11) + F ubni (2) + F tlō (1) + F wō (3) + $\mathrm{F}$ pwō $(5)=84$

$5-\mathrm{N}$ ja $(41)+\mathrm{N}$ ubni $(4)=\mathbf{4 5}$

$6-\mathrm{N}$ a (41) $+\mathrm{N}$ wa (1) $+\mathrm{N}$ pwa $(3)=\mathbf{4 5}$

Ближняя периферийная зона: 7 - F ōn (14) + F jōn (6) = 20

$8-\mathrm{M} \mathrm{u}(3)+\mathrm{M}$ tu (9) $+\mathrm{M}$ ōpu (5) $=17$

$9-\mathrm{M}$ assu $(9)+\mathrm{M}$ inassu $(2)=\mathbf{1 1}$

Дальняя периферийная зона:

$10-\mathrm{M} \mathrm{i}(\mathbf{1 0})$

$11-\mathrm{M}$ a $(\mathbf{8})$

$12-\mathrm{M}$ in $(5)+\mathrm{M}$ jin $(1)=6$

$13-\mathrm{M}$ ja (1)

$14-\mathrm{M}$ wa (1)

$15-\mathrm{N}$ in $(\mathbf{1})$

С учетом новых данных прежняя схема теперь может быть представлена в следующем виде.

Схема 2. Словообразовательное поле абстрактности в готском языке (вариант 2).

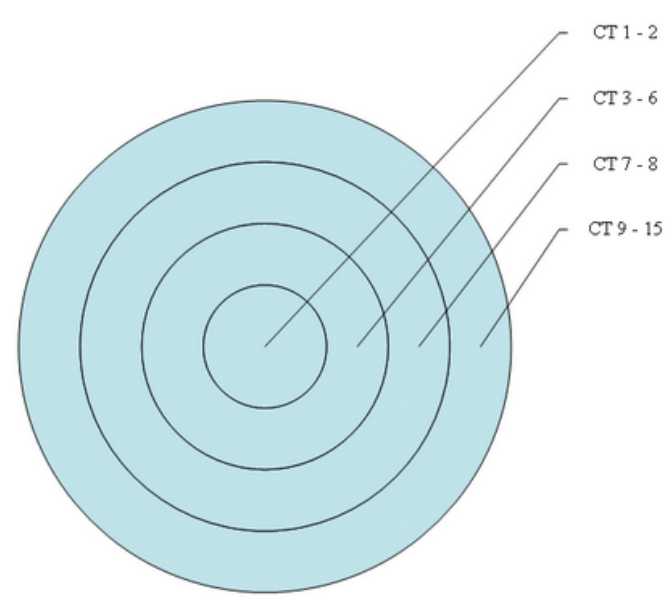

Таким образом, можно заключить, что наиболее прототипичными словообразовательными типами в готском языке можно считать модели $\mathrm{F}$ ein от имен и F eini, aini, ōni от слабых глаголов. Обе модели относятся к наиболее молодому слою словообразовательных типов АИ / ОИ, считаются германскими инновациями и используют суффиксы, содержащие консонантный элемент -n- с различной огласовкой.

Конкуренцию им составляют модели 3 и 4, которые хронологически относятся к наиболее древнему слою словообразовательных типов. В модели 3 все производные имеют парадигму основ на -і, образованы от готских сильных и претерито-презентных глаголов (за исключением CT F dup), а также частично от и.-е. корней, и содержат унаследованные из общеи.-е языкового состояния суффиксальные элементы, в готском приравненные к основообразующим суффиксам. Модель 4 содержит производные с парадигмой о̄-основ, образованные в равной 
мере от готских имен прилагательных (с суф. -іра-) и глаголов (со всеми остальными суффиксами). Суффиксы указанных СТ также относятся к числу древнейших и часто уже неотчетливо выделимы в морфологической структуре слова. Примечательно, что все описанные модели - это производные женского рода.

С достаточно большим отрывом в продуктивности за ними следуют модели 5 и 6, которые включают производные среднего рода. Тон среди данных моделей построения задают СТ с основообразующими суффиксами -ja- и -a-, другие же выявленные в структуре слов суффиксы относятся к числу древних и.-е. формантов, продуктивность которых в готском языке уже не рассматривается.

Дробление периферии на ближнюю и дальнюю зоны вызвано, прежде всего, количественными данными, которые демонстрируют полный упадок продуктивности ряда моделей из дальней периферийной зоны, например, СТ с 10 по 15, которые имеют отношение к производным мужского рода и в качестве словообразовательного средства используют парадигму в целом. Это обстоятельство настойчиво привлекает внимание к тому, что АИ / ОИ прототипически мыслятся, прежде всего, как имена женского, а затем - как имена среднего рода.

В ближней периферии представлены СТ, которые, с одной стороны, демонстрируют низкую продуктивность моделей ж.р. с основообразующими суффиксами, как считается, древнегерманского происхождения (тип 7 - F ōn (14) + F jōn (6) = 20), а с другой стороны, модели м.р. с наивысшей для группы имен м.р. степенью продуктивности (тип $8-\mathrm{M} \mathrm{u}(3)+\mathrm{M}$ tu (9) + M ōpu (5) = 17 и тип $9-\mathrm{M}$ assu (9) + M inassu (2) = 11). Тип 8 продолжает и.-е. модель, а тип 9 является ее развитием в общегерманский период.

На последующем этапе исследования изучение интенсионала смоделированного поля предполагает анализ словообразовательных типов с точки зрения отражаемых ими в материальной структуре лексических единиц пропозициональных структур и дальнейшее структурирование поля с учетом степени удаленности смыслового рисунка каждого словообразовательного типа от прототипической пропозиции.

Подводя итог, в целом, можно утверждать, что полевый метод, преимущества которого неоднократно отмечались отечественными и зарубежными лингвистами, при анализе словообразовательной категории может иметь большую объяснительную силу при попытке полно и системно представить способ языковой интерпретации определенной области внеязыковой действительности. Исследование, выполненное в диахроническом аспекте, позволяет приблизиться к реконструкции содержательного начала самой словообразовательной категории абстрактности / отвлеченности в целом, выявлению ее внутренней структуры, сетки ее субкатегорий, направлений видоизменения и развития.

\section{Литература}

Араева Л.А. Словообразовательный тип. М., 2009.

Введение в германскую филологию: учебное пособие / Сост. Дронова Л.П. Томск, 2008.

Гулыга Е.В., Шендельс Е.И. Грамматико-лексические поля в современном немецком языке. М., 1969. С. 133-149.

Гухман М.М. Готский язык. М., 1958.

Демьянков В.3. Теория прототипов в семантике и прагматике языка // Структуры представления знаний в языке. М., 1994. С. 32-86.

Земская Е.А. Словообразование как деятельность. М., 1992.

Ильиш Б.А. История английского языка. М., 1958.

Караулов Ю.Н. Общая и русская идеография. М., 1976.

Кобозева И.М. Лингвистическая семантика. М., 2000.

Кубрякова Е.С. Язык и знание. М., 2004. 
КСКТ - Кубрякова Е.С., Демьянков В.З., Панкрац Ю.Г., Лузина Л.Г. Краткий словарь когнитивных терминов. М., 1996.

Логутенкова Т.Г. Историко-типологическое исследование германских литературных языков донационального периода (на материале древнеанглийского, древневерхненемецкого и древнеисландского языков). Тверь, 1993.

Резанова 3.И. Функциональный аспект словообразования: Русское производное имя. Томск, 1996.

Скребцова Т.Г. Оппозиция «центр - периферия» в лингвистических учениях // Central and Eastern European Online Library Source: Respectus Philologicus. Issue 12 (17). 2007. Р. 47-52. [Электронный ресурс]. Режим доступа: www.ceeol.com

Сравнительная грамматика германских языков / Ответ. ред. М.М. Гухман. M., 1963. T. 3.

Щур Г.С. Теория поля в лингвистике. М., 1974.

Casaretto A. Korpussprachen und Produktivität: Einige überleungen zu den gotischen s-Stämmen // Historische Sprachforschung. Göttingen, 2000. Bd. 113. H. 1/2. S. 210-238.

Stekauer P., Lieber P. The Handbook of Word-formation. Springer, 2005.

\section{Список принятых сокращений}

АИ / ОИ - абстрактные / отвлеченные имена существительные

Да. - древнеанглийский

Ди. - древнеисландский

Двн. - древневерхненемецкий

И.-е. - индоевропейский

Основ. суф. - основообразующий суффикс

СК - словообразовательная категория

СТ - словообразовательный тип

Суф. - суффикс

$\mathrm{F}$ ein - существительное женского рода, образованное при помощи суффикса -ein-

M assu - существительное мужского рода, образованное при помощи суффикса -assuja-

$\mathrm{N}$ ја - существительное среднего рода, образованное при помощи суффикса - 